\title{
Rare Occurrence Of Dermoid Cyst In Postauricular Region: A Case Report
}

\author{
Dr Uma Shankar, Dr Avinav Sarmaik, Dr Reena Kumari \\ Department of ENT, MH Gaya, India \\ DOI: 10.29322/IJSRP.10.05.2020.p10157 \\ http://dx.doi.org/10.29322/IJSRP.10.05.2020.p10157
}

\begin{abstract}
Dermoid cyst, Epidermoid cyst and Teratoid cyst are congenital lesions which are histologically related and frequently found in ovaries and scrotal region. The rate of occurrence in craniofacial region is quite low. It is very rare to encounter a true dermoid cyst in postauricular region. A case of unusual presentation of peripheral dermoid cyst in postauricular region is reported here with discussion regarding clinicopathological features and types. Emphasis is on early diagnosis, evaluation and complete excision keeping in mind associated complications and carcinomatous transformation.
\end{abstract}

Index Terms- Dermoid cyst, Epidermoid cyst, Teratoid cyst, Sack of marbles

\section{INTRODUCTION}

$\mathrm{D}$ ermoid cysts are congenital lesions. They have an epithelial lining and contain ectodermal or mesodermal derivatives. ${ }^{1}$ About $7 \%$ of these involve head and neck with varying degrees of predilection to the orbit, nose or floor of mouth. A dermoid cyst occurring in postauricular region is a rare entity, mandates sound clinical evaluation and complete excision to avoid recurrence. We are reporting a case of postauricular dermoid cyst owing to the rarity of the lesion. Various aspects related to the pathology and management are discussed.

\section{CASE REPORT}

52 years old female presented with complaints of swelling behind her left ear for past 3 years. The swelling was insidious in onset, gradually progressive in size, occasionally painful and persistent. There was no history of fever, preceding trauma or discharge from the swelling. On examination, a single globular swelling (Figure-1) about $2 \times 2 \mathrm{~cm}$ in size was noted in the left post aural region with no overlying skin changes or pulsations. It was non tender, soft, had dough like consistency on palpation and was mobile. Her general physical examination revealed no significant abnormality. There was no other ENT complaint. Ultrasonography was performed as a preliminary investigation to rule out any bony defect. After thorough pre anaesthetic evaluation, the patient was taken up for Excision of the swelling under local anaesthesia. Intraoperatively, a cystic mass with pale yellow smooth surface was found in subcutaneous plane, free from surrounding tissue. The cyst was removed in-toto. The cyst was cut open to reveal pultaceous material inside with hair (Figure-1). The specimen was sent for histopahtological examination.
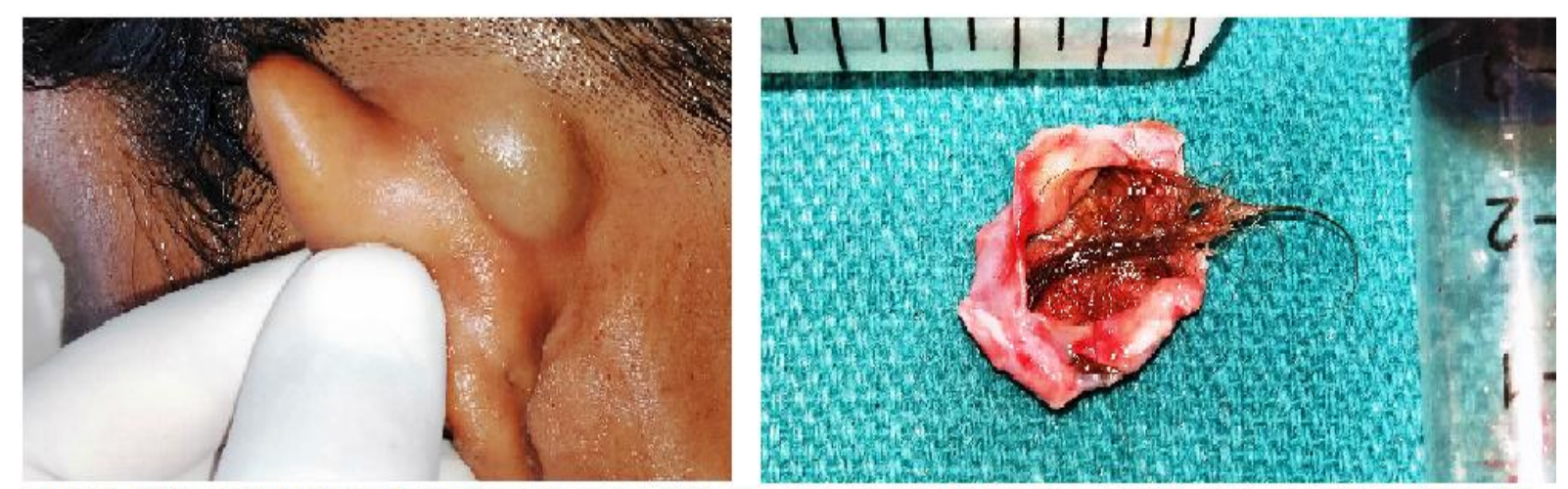

Figure 1. (a) Swelling involving left postaural region. (b) Cut open specimen post excision reveals presence of hair in the cyst.

The surgical wound healed well and sutures were removed after 7 days. The patient remained asymptomatic during her follow up visits and has developed recurrence or other fresh complaints over last 18 months while compiling of this report.

Histopathological Examination: Gross- The specimen was oval in shape, yellowish white in colour, cystic in consistency and measured $1.5 \times 1 \times 1 \mathrm{~cm}$. On cut section, thick greasy yellowish coloured material seen. Multiple blackish hair noted. On palpation, the cyst wall appeared thickened at some places. Microscopy- HPE showed Keratinised stratified squamous epithelium along with multiple hair shafts and sebaceous glands. Focal areas showed collection of mesodermal elements in the form of immature cartilaginous cells. 

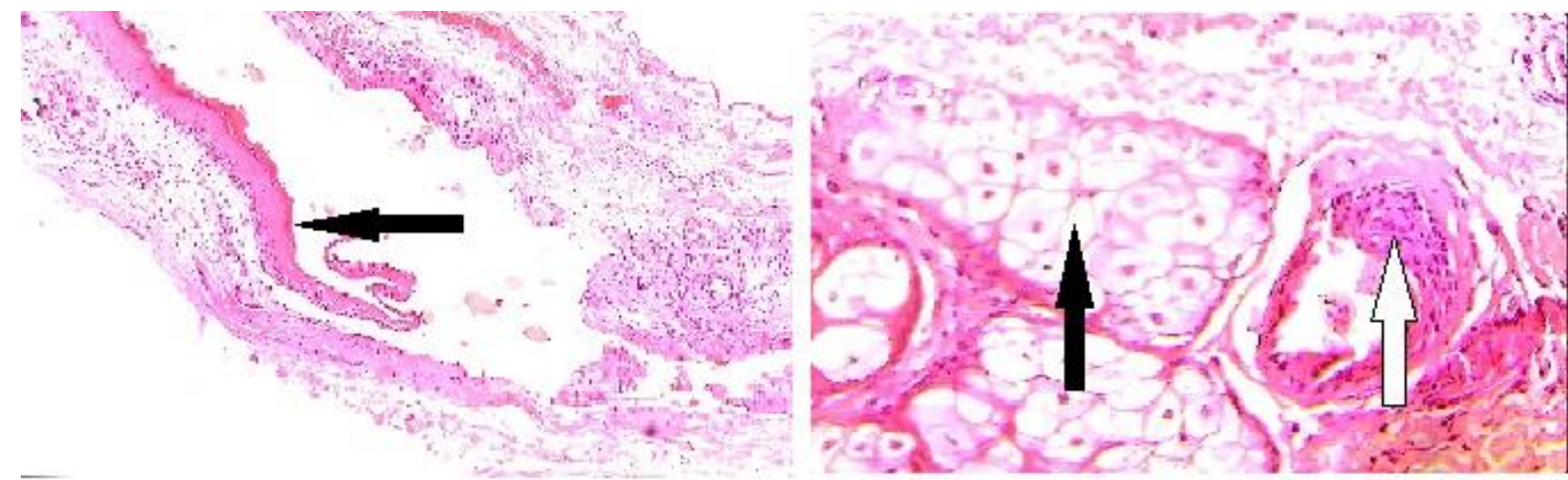

Figure 2. (a) Arrow showing keratinising stratified squamous epithelial lining of cyst wall. (b) Sebaceous glands (black arrow) and hair bulb (white arrow).

\section{DISCUSSION}

Dermoid cyst or true dermoid cyst or compound cyst as defined by Batsakis is an epithelial lined cavity with variable number of skin appendages (hair, follicles, sebaceous glands, etc. $)^{1}$. Other two histologically related clinicopatholgical lesions of developmental origin are Epidermoid cyst and Teratoma. Epidermoid cyst is lined with simple squamous epithelium with a fibrous wall and has no adnexal structures while a Teratoid cyst lining ranges from simple squamous to ciliated epithelium and may contain derivatives of all three germ layers. ${ }^{2}$ The dermoid cyst originate from congenital inclusion of germ layers in the deeper tissues along the lines of embryonic fusion. Other theories proposed include entrapment of ectodermal tissue of the first and second branchial arches during fetal development or previous surgery or injury leading to traumatic implantation of epithelial cells into deeper tissues. Dermoid cyst as a variant form of thyroglossal duct cyst has also been postulated. ${ }^{3}$

Dermoid cysts are frequently found in ovaries and testicles. Rarely do they present in head and neck region (about 7\%) during second or third decade of life as subcutaneous swellings, firm, rubbery, mobile and gradually increasing in size. They are usually painless and may be associated with pain in case of recurrent infections in the cyst. Gradual accumulation of cellular debris, sebum and hair causes characteristic slow growth. New and Erich classification based on the site suggests four types for craniofacial dermoid cysts with occurence:

(1) In the eyes and orbits,

(2) In the nose area,

(3) In the floor of mouth, submental and submaxillary regions

(4) Miscellaneous group

It is rare to encounter dermoid cysts in auricular or postauricular region. New and Erich in their analysis of 1495 patients did not report even a single case of postaural presentation of the cyst. ${ }^{4}$ Various studies have reported prevalence rate of $9.9 \%$ ( out of 231 cases), 3\% (out of 33 cases) and $5.5 \%$ (out of 183 cases). ${ }^{5}$ The peripheral dermoid cysts comprise $80 \%$ of the dermoid cysts and form during calvarial maturation near suture lines. They may erode underlying bone but an intracranial involvement in highly unlikely. On the other hand, midline dermoid cysts are associated with persistent fusion of underlying dura to the overlying ectoderm. During fetal development the latter gets dragged with dura creating an intracranial connection and forms an inclusion cyst. ${ }^{6}$ Peripheral cysts may thus pose no problem during clinical evaluation. However, it is imperative to radiologically ascertain intracranial connections in midline cysts. USG findings for dermoid cyst comprise solid and cystic structures within a heterogenous mass. ${ }^{7}$ Unilocular masses filled with a homogenous, hypoattenuating fat nodules give "sack of marbles" appearance on CT scan. ${ }^{8}$ Fine Needle Aspiration Cytology also facilitates to distinguish these from other lesions like epidermoid inclusion cyst, sebaceous cyst, subperiosteal abscess, lymphadenopathy, trichilemmal cyst, lipoma and hemangioma. ${ }^{9}$ Histopathologically, the cyst contains pulatceous material with hair. Microscopical examination reveals presence of stratified squamous epithelium, sebaceous glands and hair follicles.

Simple excision remains the mainstay management for peripheral cysts while a coronal approach with frontal craniotomy for complete excision may be required for midline inclusion cysts with a multidisciplinary team including a neurosurgeon. ${ }^{10}$ Excision of dermoid cyst is warranted to prevent secondary infection, neurological complications in midline cysts and avoid functional complications depending on the site of presentation like proptosis, diplopia, restricted eye movement (eye and orbit), dysphagia, difficulty breathing and dysphonia (intraoral and neck). Better aesthetics remain a major indication for excision. Although benign lesions, dermoid cysts have been reported to undergo carcinomatous transformation. ${ }^{11-14}$ Recurrence may be encountered after incomplete excision or in case of infected cyst. Therefore, need for early diagnosis, evaluation and complete excision is emphasised for such lesions.

\section{CONCLUSION}

Dermoid cysts of postaural region are a rare entity. The management for peripheral occurring lesions may not require extensive evaluation before excision however, a midline lesion should rare suspicion for intracranial involvement. The latter may require multidisciplinary team management. Recurrence may occur in case of incomplete excision or infected cysts. Malignant transformation has been reported in some cases. ${ }^{11-14}$

\section{REFERENCES}

[1] Batsakis JG. Tumors of the Head and Neck, $2^{\text {nd }}$ ed. Baltimore. Williams and Wilkins, 1979:227-8. 
[2] Jham BC, Duraes GV, Jham AC, Santos CR. Epidermoid cyst of the floor of the mouth: a case report. J Can Dent Assoc 2007;7:525-8.

[3] Mirza S, Fadl S, Napaki S, Abualruz A. Case report of complicated epidermoid cyst of the floor of the mouth. Radiology- histopathology correlation. Quatar MED J 2014;2014:12-6.

[4] New GB, Erich JB. Dermoid cyst of head and neck. Surg Gynecol Obstet 937;65:48-55.

[5] Tanahira A, Kobayashi T. Recent Six- year statistics of plastic surgery practices at Kumamoto Rosai Hospital. Jap J Kumamoto Igaku 1980;54:99103.

[6] Durma A, Yildiogl U, Polat B, Binar M. A middle cranial fossa dermoid cyst treated by an endonasal endoscopic approach. J Craniofac Surg. 2015:26(4):e333-5.

[7] Bataineh AB, Mansour MJ. Extraoral epidermoid cysts. Br J Oral Maxillofacac Surg. 997;35:49-51.

[8] Pancholi A, Raniga S, Vohra PA, Vaidya V. Midline submental epidermoid cyst: a rare case. Int J Otolryngol.2006;4(2):74-77.

[9] De Soa BA, Dey C, Carver N. A rare case of dermoid csyt behind the ear. Plast Reconstr Surg.2003;112(7):1972.

[10] Pfaff MJ, Bickerton S, DiLuna M, Steinbacher DM. Transcrania nasoethmoidal dermoids: a review and rational for approach. J Plst Reconstr Aesthet Surg. 2013;66(12):1725-31.
[11] Dayananda Rao B, Prabhaka V, Jagannatha Rao MV, et al. Intraorbital dermoid with malignant metaplasia. Indian J Opthalmol 1976;23:2-3.

[12] Stephnson GC, Ironside JW. Squamous cell carcinoma arising in a subcutaneous dermoid cyst. Postgrad Med J 1991;67:84-6.

[13] Kbayashi T, Kuchiwaki H, Inao S, et al. A squamous cell carcinoma originated from intracranial dermoid cyst. Neurochirurgia 199;36:26-9.

[14] Devine JC, Jones DC. Carcinomatous transformation of a sublingual dermoid cyst. A case report. Int J Oral Maxillofac Surg 2000;29:126-7.

\section{AUTHORS}

First Author - Dr Uma Shankar, MBBS MD, MH GAYA, druspandey@gmail.com

Second Author - Dr Avinav Sarmaik, MBBS MD, MH GAYA, avcarpediem@yahoo.com

Third Author - Dr Reena Kumari, MBBS, NMMC Airoli, ojha.dr.reena@gmail.com 